This is a postprint version of the following published document:

Corcoba Magaña, Víctor; Muñoz-Organero, Marío (2015). “GAFU: Using a gamification tool to save fuel", in IEEE Intelligent Transportation System, Volume:7, Issue: 2, Pages: 58 - 70.

http://dx.doi.org/10.1109/MITS.2015.2408152

(C) 2015. IEEE. Personal use of this material is permitted. Permission from IEEE must be obtained for all other uses, in any current or future media, including reprinting/republishing this material for advertising or promotional purposes, creating new collective works, for resale or redistribution to servers or lists, or reuse of any copyrighted component of this work in other works. 


\title{
GAFU: Using a gamification tool to save fuel
}

\author{
V. Corcoba Magaña and M. Muñoz-Organero \\ Departament of Telematic Engineering, University Carlos III, Leganés, Spain \\ E-mails:vcorcoba@it.uc3m.es, munozm@it.uc3m.es
}

\begin{abstract}
In this paper, we propose, implement and user-validate a training tool for saving fuel that uses some elements from games in order to promote efficient driving and provide feedback to the user. The proposed system uses a fuzzy logic system in order to assess the driving style from the point of view of the fuel consumption. The output is a score between 0 (not efficient) and 10 (efficient). This value can be compared with the scores obtained by other users of the solution that have similar characteristics in order to do a fair comparison and to obtain ecodriving advices adapted to the user's context and environment (e.g., braking frequency is greater on urban road than highway). Providing feedback to the user is essential in ecodriving systems for changing bad driving habits and not returning back to them. In our case, the system provides two types of feedback. The first type of feedback is provided in real time. When the user does not comply with some of a preconfigured set of eco-driving rules, he or she gets a warning message. The second type of feedback is based on a calculated relative score for each user according to his or her driving style, positioning the user into a ranking of eco-driving users and generating a set of eco-driving tips. A validation experiment has been conducted with 36 participants on three different routes in Spain. The results show that the use of gamification tools and techniques in eco-driving assistants helps drivers not to lose interest for fuel saving and helps them not to return back to their previous bad driving habits.
\end{abstract}

\section{Introduction}

The driving style has a direct effect on the fuel consumption of vehicles. An aggressive driver demands and wastes a lot of energy. Driving without exceeding a speed limit, smoothly des/ accelerating, properly changing gears and maintaining a relatively constant speed provide a positive contribution in saving fuel and reducing greenhouse gas emissions. Adopting an efficient driving style, drivers can save up to $25 \%$ of fuel [1] [2].
In addition, it improves comfort, reduces the risk and severity of accidents and there is less degradation of vehicle components. However, the percentage of fuel savings depends on the type of vehicle. In modern vehicles, it could be less important. For example, some vehicles include a system that automatically adjusts the acceleration regardless of the intensity with which the user presses the throttle pedal. For the driver to change his driving style to a more efficient one, motivation is a very important factor. In recent years, governments tend to require that a driver drives efficiently in order to get the driver' s license. 
For example, in Spain since January 21, 2013 the examiner assesses whether the student drives at high RPM, anticipate traffic flow and accelerates or brakes smoothly. However, the effectiveness of this learning depends on stimulation. There are several studies that have observed a certain degree of deterioration in fuel efficiency over time [3] because drivers return back to their previous bad driving habits. Driving is a very complex activity in which the driver has to perform multiple tasks at the same time, so it is usual that the driver does not worry about fuel economy. Continuous feedback is necessary and it can be supplied through the new technologies introduced in the vehicles such as: vehicle's Controller Area Network (CAN) bus, On board Diagnostic Port (OBD), On Board Vehicle Systems, Smartphone, and Vehicle-to-vehicle network (V2V). In [4], the authors propose a device that provides real-time audio and visual feedback to the driver in order to improve his/her driving style. The solution warns the driver when he or she is driving aggressively. In addition, the driving assistant recommends to change gear when it detects the driver is not driving economically. The system was tested on 15 vans belonging to various companies in the UK and over $39,000 \mathrm{~km}$ of data was collected. It was observed that use of the device saved an average $7.6 \%$ of fuel. However, we have taken into account that eco-driving assistant can have a negative effect on driving when they do not provide the correct feedback [5]. Eco-driving systems have to be non-intrusive and not to require high-demanding user attention. In addition, the system should clearly show fuel savings achieved when using the system to encourage the adoption by the user.

One way to motivate the user to save fuel is using gamification. Gamification consists of using game techniques in a non-game context to perform arduous and repetitive activities. This improves the engagement of the user. In [6], we can see a review about gamification and the impact on teaching. There are many scenarios where this concept is applied. For example in [7], authors used emoticons and sounds to encourage the recycling of bottles. The emoticon smiles when a user throws away a bottle in the garbage. They conclude that the proposed system increases the recycling rate by a factor of 3 . In [8] the authors propose an application to report road accidents. The application uses a game layer to motivate drivers to use it and make it more fun. Another example is INNOV8 [9]. INNOV 8 is a game developed to teach new employees the IBM Business Process Management. This software trains employees without spending money on transportation for a teacher. Besides, the results are even better than those obtained with traditional methods.

Gamification has become very important in recent years. Figure 1 shows the evolution of gamification as a search term according to Google Trends. The numbers on the graph reflect how many searches have been done for a particular term, relative to the total number of searches (for that concept) done on Google over time. They don't represent absolute search volume numbers, because the data is normalized and presented on a scale from 0-100. Each point on the graph is divided by the highest point, or 100 .

Moreover, social networks in combination with gamification techniques can positively influence the driver's motivation to save fuel. A method for utilizing fuel consumption data in an incentive system for the Tampere City Transport based on sharing individual driver's average fuel consumption in a specific group compared to the average fuel consumption of all drivers in that specific group was proposed in [10]. A different social awareness system to promote ecodriving was presented in [11]. The system obtains information about the driving styles using both GPS and motions sensors. Then, communication technology is employed in order to promote eco-driving and safe-driving. The information was made available through a web site and some social experiments for the promotion of eco-driving and safe-driving were implemented. In [12], the authors propose a social networking platform that uses gamification techniques and tools in order to promote ecology. Users register ecological actions to earn points. The actions performed by each user are posted on the timeline of the website where all the actions performed by the user's friends are shown. In addition, the activity may be shared with other external social networks. The people who used the application said that the system helped them to have fun when they recycle. However, this solution has many problems. First, the user has to manually register the ecological actions, so he or she may be less motivated than in the case of automatic registration. In addition, we have to trust in the user truthfulness. On the other hand, the scoring system is subjective since it depends on the score that other users assign. It also does not take into account the characteristics of the vehicle or the environment conditions.

This paper presents the implementation and user validation of a training tool for saving fuel that uses some elements from the games. In that case, the challenge is to comply with the following rules during the trip:

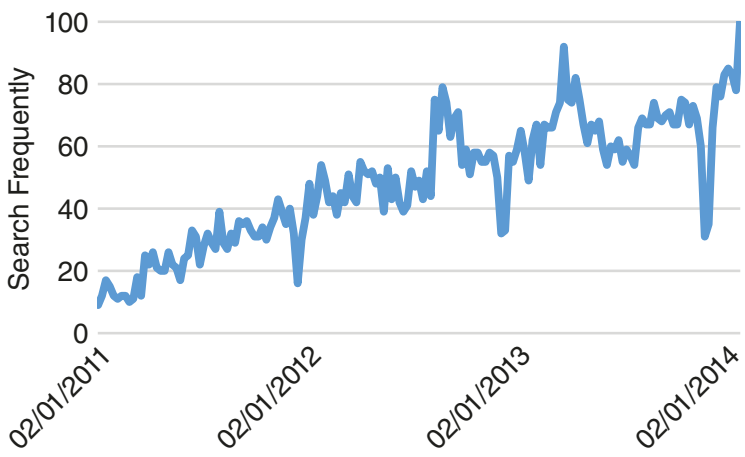

FIG 1 Evolution of "Gamification" as a search term. Source: Google Trends. 
- Driver must not drive at high speed

- Avoid braking or accelerating sharply

- Avoid braking or accelerating unnecessarily

- User should drive at steady speed

- Engine speed should be low

The solution employs the following gamification tools:

Score: It will be determined by the degree of compliance

with the eco-driving rules and the fuel consumption. Moreover, the proposal indicates to the users what improvements they should make in their driving style in order to improve it. Therefore, we avoid the notion that the score comes from a black-box.

Relative Leaderboard: The ranking position depends on the score in the evaluation of the user's driving style. The leaderboard only shows the points obtained by other drivers under similar conditions in order to make a fair comparison. This gamification tool lets drivers compete to obtain a higher ranking by complying with more eco-driving rules. This could be a source of motivation for competitive drivers. In addition, it can provide:

Recognition

An incentive to improve

Social proof

A sense of belonging to a community

Simplicity

Badges: They are elements that allow us to define goals that have a positive impact on fuel consumption. Driver can check the list of unlocked achievements and compare them with those of another user with similar characteristics. This gamification tool could drive more direct competition between two specific players who are trying to beat each other. In addition to the benefits of the leaderboards, this method can provide instructions about what type of driving behavior minimizes the energy demands. This function is useful for the learning process.

This paper experimentally validates the results by deploying the eco-driving assistant on 3 different models of vehicles with different drivers on different environments. The diagnostic port (OBD2) [13] that is present in most of today's vehicles is used to evaluate the eco-driving rules and to obtain fuel consumption.

\section{State of the Art}

There are many references in related literature about Ecodriving, showing its benefits for reducing fuel consumption and emission of gas pollutants while increasing safety, from former studies that show how the implementation of certain eco-rules improve fuel consumption and gas emissions such as [14] [15] to recent proposals that use some of the vehicle's surrounding elements information such as the traffic flow state and upcoming traffic signals to anticipate optimal acceleration and deceleration patterns such as [16] [17].

Basically, eco-driving is based on the assumption that providing eco-driving advice to the driver positively cor- relates with the decrease in fuel consumption. All major related references try to somehow prove this assumption. There are several ways and mechanisms that have been used to tackle this issue.

The authors in [15] analyzed the influence of the driving style and road characteristics on greenhouse gas emissions and fuel consumption. Their conclusions were that if eco-driving advices are used, fuel consumption can be decreased from 5 to 25 per cent. On the other hand, they observed that on some occasions, drivers misinterpret the eco-driving advices adopting a driving style less efficient than the one that they previously had. The study also highlighted the need to continuously motivate the drivers because many of them consider eco-driving styles "boring".

Other authors [14] [18] also observed that drivers forget or do not feel motivated to apply their knowledge. Continuous feedback improves and maintains the effects achieved by learning [19] [20] and should be consider in the design of any eco-driving assistant.

Showing instantaneous fuel consumption feedback to the driver could be enough to promote the use of eco-driving styles [18]. The results from 20 samples of drivers in Southern California [21] showed that on average the fuel economy on city streets improved by $6 \%$ while the fuel economy on highways improved by $1 \%$.

Several eco-driving and eco-routing solutions need fuel estimation models. The authors in [22] proposed an algorithm for estimating the fuel consumption which takes into account the number of stops, average speed, gear, friction coefficients and several engine parameters.

On the other hand, some authors try to find control strategies to optimize fuel consumption. The research in [23] proposed a control strategy to drive efficiently that employs dynamic programming to determine which is the adequate speed and adequate gear at any given time.

Another way to save fuel is to identify the most common vehicle type travelling on the road in order to predict the traffic flow and reduce the greenhouse gas emissions. In [24], the authors propose to use neural network to classify vehicles. Vehicle classification data are very useful for the pavement design, pavement-maintenance scheduling, commodity flow analysis, highway-capacity analysis, weight enforcement, and environmental analysis.

There are also studies that analyze the impact of ecodriving assistant and the fatigue experienced by drivers. The study in [25] realized a comparison between the fatigue experienced during normal driving and the fatigue caused by eco-driving. The conclusions were that if we use an ecodriving assistant, the fatigue will be lower than normal driving or eco-driving friendly driving without assistant.

Sometimes, eco-driving may come into conflict with safety. For example, reducing the use of the brakes and circulating at a higher gear could have adverse effects on the control of the vehicle. The authors in [26] identified a set of 
factors associated with the vehicle, the driver and the environment that could affect the safety and/or energy consumption. However, there are a number of factors that influence in a positive way both for safety and fuel consumption. Authors in [26] observed that following a training program about eco-driving reduces the number of accidents (25\%), fuel consumption (11\%) and greenhouse gas emissions (from 23\% up to $50 \%$ ). Improving safety and energy consumption at the same time, as well as maximizing the traffic throughput or a certain road is also behind projects such as the Google Driverless Project [27] and the EU funded SARTRE project [28].

There are also some works that focus their attention on predicting the near future constrains for the vehicle in order to be able to anticipate the driver's behavior to optimally fulfil them from the fuel consumption point of view. The authors in [17] calculate, using model predictive control, the appropriate vehicle control input based on vehicle fuel consumption model, anticipation of the preceding vehicle and status of traffic signals in a varying road-traffic environment for ecological driving. The authors however only validate the results by simulation and not in a real environment. The authors in [16] propose a system to provide real-time advice based on changing traffic and infrastructure conditions by adjusting the speed of the vehicle if the information of the timing in upcoming traffic lights is known. A similar system that optimizes fuel-consumption based on the knowledge of the timing of the traffic lights has recently been proposed in [29]. The potential impact of such a system is only simulated.

One of the major issues related to anticipation to the near future constrains is the ability to detect and recognize traffic signals [30]-[32].

The technological evolution in mobile devices makes them a suitable platform for implementing eco-driving assistants. The authors in [33] describe a mobile phone application that uses GPS function to promote eco-driving. The proposed application is suitable for automobiles that are not equipped with an eco-driving monitoring system. The authors in [34] proposed a system that used embedded sensors in mobile devices for road surface monitoring.

\section{Awareness Game for Fuel Saving}

In order to motivate the driver to adopt an efficient driving style, we propose to use gamification tools. The main research question addressed by the proposed system is to validate and quantify the positive impact on fuel consumption when we compare the driving style of users that have similar features. The solution uses vehicle telemetry and environment information for clustering users who have major characteristics in common.

Then, a ranking among the users in each cluster is made. The ranking position depends on the score in the evaluation of the user's driving style. A fuzzy logic system is used to assess the driving style. The output is a value between 0 (inefficient driver) and 10 (efficient driver). Finally, we com- pare each member of the cluster with the best driver getting the eco-driving tips to improve his position in the ranking, and therefore, to save more fuel.

The user receives two types of feedback. The first type of feedback is provided in real-time when the driver does not comply with the eco-driving rules. Real-time feedback is very effective since it allows the user to correct the negative actions without having to remember the eco-driving advice provided by the system. The second type of feedback takes place when the trip finishes and the system reports about: user score, the position in the ranking, fuel consumption and what actions should be performed to improve the driving style.

Google play services [35] is used to implement the leaderboards and the achievements. Drivers can compare their score and badges with friends or other users of the application. Google allows us to add new contacts who are playing with the application. Therefore, the application helps to expand the friend's network.

The second type of feedback is based on social incentives, so they are essential to encourage the user for using the system and applying the eco-driving advices.

Figure 2 shows a schema of the proposed system. In the following subsections, we describe each component of the proposed awareness game.

\section{A. Identification of Users with Similar Characteristics}

Fuel consumption and driving style depend on many factors such as: traffic state, weather conditions, road type and vehicle. Comparing driving styles is a very complex task. Therefore, direct comparison of drivers may give inaccurate results. In our case, we propose to cluster drivers taking into account the following attributes:

Average Speed (Km/h): Average speed allows us to group users who have taken a trip on roads with comparable speed limits. The speed limit of the road allows us to determine the type of road where the vehicle is located.

Time: They have an influence on fuel consumption and driving style. In the rush hour, it is frequent that fuel consumption and de/acceleration increase. Moreover, average speed falls. These negative actions are not due to bad driving habits. They are caused by external environment conditions. Although, the route and vehicle is the same, the fuel consumption changes in each test at different hours. To make the comparison fair, it is appropriate to compare the samples that are obtained in a similar time interval.

Weather conditions and traffic events: when weather conditions are adverse, the vehicle speed decreases. Under these conditions, it is usual to confront traffic jams, increasing the accelerations and slowdowns. In addition, fuel consumption can increase due to changes in aerodynamic resistance. These factors are unrelated to the driver, but however can produce large changes in comparison with data obtained under normal conditions, so we must have them in mind when we evaluate the driving style. The system obtains the 


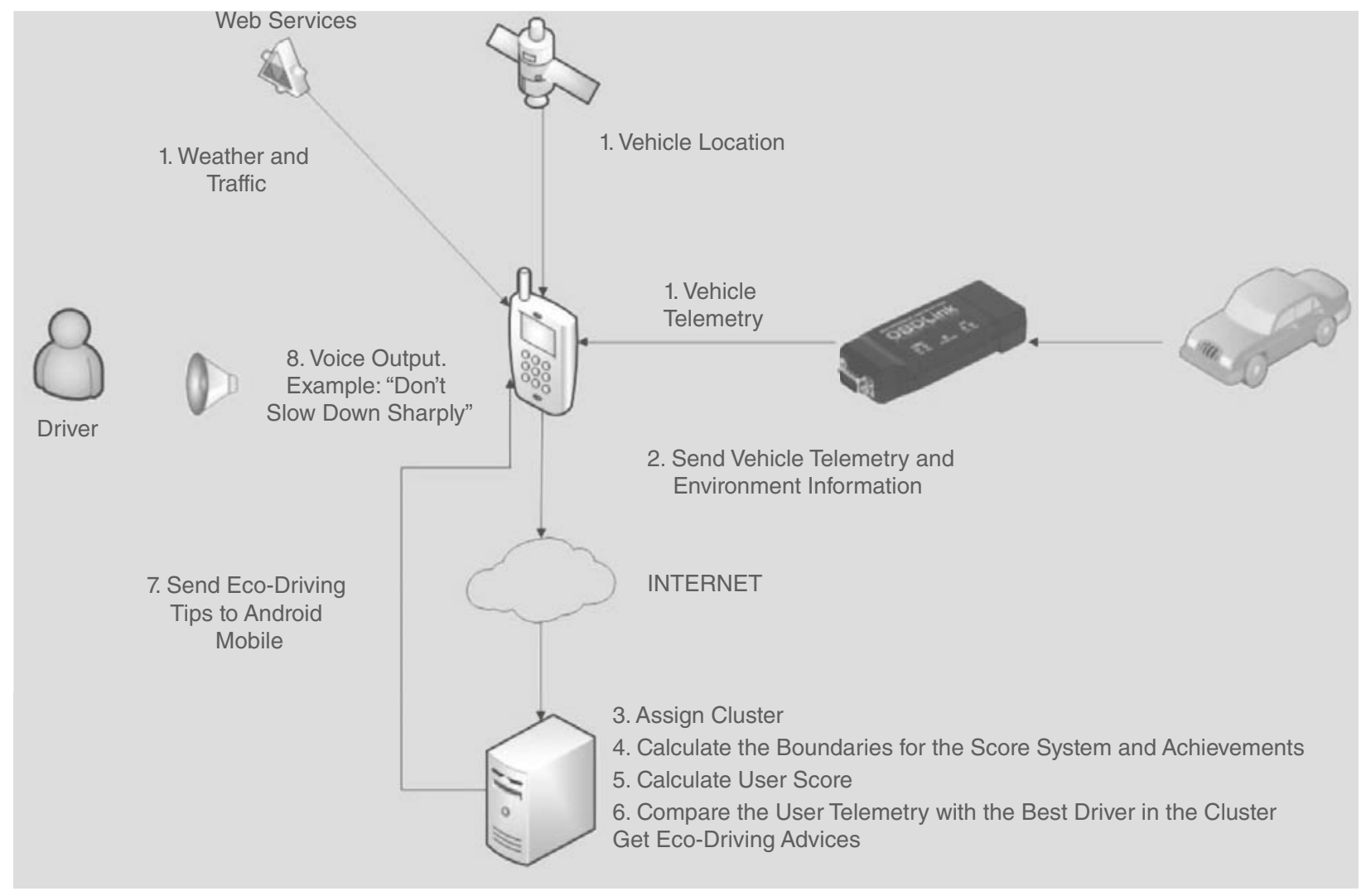

FIG 2 Awareness game architecture.

road incidents and weather conditions from web services (DGT and AEMET) [36] [37]. The received xml files are processed using the XML API which Android provides. Table 1 shows the variables that are taken into account when we build clusters.

Trip distance: the length of the route is a factor that may influence in the evaluation of the driving style. If the trip is short, inefficient actions can have a greater impact on the final result.

Percentage of time driving over $50 \mathrm{~km} / \mathrm{h}$ : This attribute is used to identify the type of road where the driver is driving. In Spain, the speed limit is $50 \mathrm{~km} / \mathrm{h}$ on urban roads. The type of road is very important to fairly compare drivers because in urban roads, accelerations and slowdowns are more frequent, resulting in an increase in fuel consumption.

Stop rate: The vehicles consume a lot of fuel when the vehicle is stopping and restarting. Therefore, this variable is very important in order to compare the drivers in a fair way. Its value depends on the distance traveled and the number of stops.

Percentage of time that the vehicle is stopped: If the vehicle is stopped by a large amount of time during the trip means that the road conditions are bad or that driver is driving on urban roads where there are a large number of traffic lights and traffic signals that force the vehicle to stop.
In this scenario, the number of accelerations (positive and negative), fuel consumption and variation in the speed will increase in comparison with the results obtained in highways or when the road conditions are good. For this reason we must bear in mind this variable to build the clusters.

Vehicle features: the impact of accelerations, decelerations, vehicle speed and engine speed depends on the vehicle type. For example, if the vehicle is old, the maximum speed from which the fuel consumption grows exponentially will be lower than in modern vehicles that have aerodynamic improvements.

\begin{tabular}{|c|c|c|}
\hline & Variable & Units \\
\hline \multirow[t]{3}{*}{ Weather } & Temperature & ${ }^{\circ} \mathrm{C}$ \\
\hline & Wind speed & $\mathrm{Km} / \mathrm{h}$ \\
\hline & Precipitation & $\mathrm{mm}$ \\
\hline \multirow[t]{4}{*}{ Road incidents } & Level & Black \\
\hline & & Red \\
\hline & & Yellow \\
\hline & & Green \\
\hline
\end{tabular}

Table 1. Weather and road variables. 
Table 2 shows fuel consumption grouped by the intensity of the acceleration using a Citroen Xsara Picasso 1.6 HDI. Table 3 captures the results for a Ford Fusion 1.4 HDI. In both cases, the driver, the route and traffic conditions were the same. We can observe in the first case that the fuel consumption increased significantly from $2 \mathrm{~m} / \mathrm{s}^{2}$, while in the second case the fuel consumption grew especially when the intensity of the acceleration was higher than $2.5 \mathrm{~m} / \mathrm{s}^{2}$. We must highlight that the vehicle weight of the Ford Fusion 1.4 HDI is lower than Citroen Xsara Picasso 1.6 HDI, therefore, the influence of the acceleration is also lower.

The results show that the vehicles features should be similar to make a fair comparison among drivers. In this paper, we take into account the following variables: vehicle weight, power engine, fuel type, drag coefficient, and age.

To group the social network users, we employ the Expectation-Maximization Algorithm (EM). This probabilistic clustering algorithm is based on obtaining the probability density function to which data belongs. For estimating the probability density function, we can use a distribution such as: Normal, t-Student, Bernoulli, Poisson, and log-normal. The distribution parameters are calculated maximizing the log-likelihood function. This function evaluates to what degree the data fit to the distribution function. This algorithm is widely used because it requires low amount of memory, is immune to noise when the dataset is large and does not need to choose a metric that it is the most critical step when it comes to clustering.

\section{B. Score System and Retrieving Eco-Driving Tips}

We calculate the user score using fuzzy logic. This method allows us to simulate the human knowledge when carrying out certain tasks such as driving. The proposed system is able to evaluate the driver's driving style based on a knowledge base and the information obtained through the vehicle's diagnostic port (OBD2). The OBD2 port allows us to obtain the vehicle telemetry. The knowledge base contains the rules (see section $\mathrm{F}$ ) that define whether driving is efficient or not. The input variables of the system are:

Percentage of sudden de/acceleration: Acceleration involves increase in energy demand and deceleration implicates energy loss. A novel or aggressive driver accelerates and slows down sharply even if the road conditions are good.

Standard deviation of the vehicle speed: When a vehicle is accelerating, it is necessary to overcome a force proportional to vehicle mass and the acceleration. During acceleration, higher acceleration or vehicle mass means more demand of traction force on the wheel, and therefore, an increase in fuel consumption. After reaching the desired speed, fuel consumption is decreased because the resistance force due to the acceleration is zero. For this reason, the driver must avoid changing vehicle speed whenever possible.

Percentage at high engine speed: The fuel flow depends on power required by the engine. When the engine is warm,

\begin{tabular}{ll} 
Acceleration $\left(\mathrm{m} / \mathrm{s}^{2}\right)$ & Fuel Consumption $(\mathrm{I} / 100 \mathrm{~km})$ \\
\hline $0.5-1$ & 6.78 \\
$1-1.5$ & 6.03 \\
$1.5-2$ & 6.13 \\
$2-2.5$ & 7.08 \\
$2.5-3$ & 7.54 \\
$>3$ & 8.17 \\
\hline
\end{tabular}

Table 2. Citroen Xsara Picasso 1.6 HDI 110 CV.

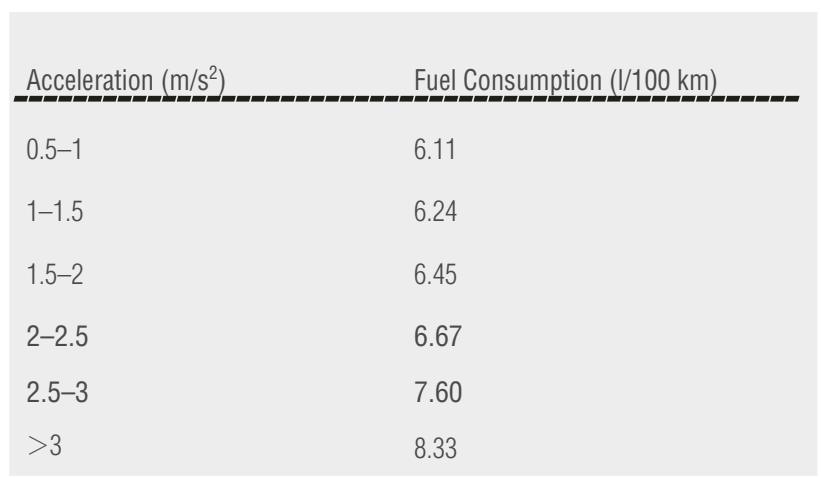

Table 3. Ford Fusion 1.4 HDI $80 \mathrm{CV}$

the energy power demand is directly related to the pedal position and engine speed (R.P.M). At the same speed, if we drive at high gear, the engine will run at lower R.P.M and consume less fuel compared to driving with low gears. For this reason, the driver should try to minimize the use of low gears.

Percentage at high speed: The fuel consumption grows exponentially when we drive at high speeds due to an increase in resistance to the movement (drag force). However, we must bear in mind that the speed limit to save fuel depends on the engine performance and aerodynamics. In the tests, driving a Citroen Xsara Picasso 1.6 HDI 90 CV, we have observed that the fuel consumption increased about $10 \%$ from $110 \mathrm{~km} / \mathrm{h}$ to $120 \mathrm{~km} / \mathrm{h}$.

PKI: This variable measures the aggressiveness of driving and depends on the frequency and intensity of positive acceleration. A low value means that the driver is not aggressive. We can find more information about metrics used to measure the smoothness of driving in [38], [39], and [40]. PKI is calculated using the following equation:

$$
P K I=\frac{\sum\left(v_{i}-v_{i-1}\right)^{2}}{d}
$$

where $v$ is the vehicle speed $(\mathrm{m} / \mathrm{s})$ and $d$ is the trip distance (meters) between $v_{i}$ and $v_{i-1}$.

The output of the system takes a value (normalized) between 0 and 10 . High score means that the driver is driving 
efficiently. We have defined two spline-based membership functions: Not Efficient and Efficient.

Rules: The rules have been obtained through observation of real samples. Our fuzzy system has six rules:

IF stdSpeed is high AND (acceleration OR deceleration OR speed) is high THEN NonEfficient

IF engineSpeed is high AND speed is low THEN NonEfficient

IF acceleration is high and PKI is high THEN NonEfficient If engineSpeed is high AND speed is high THEN Efficient If stdSpeed is low AND acceleration is low AND PKI is low THEN Efficient

If stdSpeed is low AND deceleration is low THEN Efficient

We can observe some rules such as "If enginespeed is high AND speed is high THEN Efficient" could come into conflict with classic eco-driving tips as "Engine speed should be low" and "Driver must not drive at high speed". However, the idea of the fuzzy system is not to penalize the high vehicle speed when the frequency of the accelerations and its intensity are not high. The high vehicle speed is inefficient when the driver has to adjust the speed, wasting energy through brakes. Otherwise, it could have a positive effect on consumption because the engine will be working for less time. Furthermore, modern vehicles include aerodynamic improvements that reduce the impact on fuel consumption. In these vehicles, the aerodynamic resistance force increases when vehicle speed is very high (greater than the usual speed in highway). On the other hand, when the driver is driving at low gear, the engine speed increases as well as fuel consumption. In this case, the high engine speed is not due to the vehicle speed. For this reason, we include the fuzzy rule: "IF engineSpeed is high AND speed is low THEN NonEfficient".

Eco-driving advice are obtained calculating the difference between the attribute values. The attributes used to perform the comparison are:

Percentage of time at high speed

Percentage of time at high engine speed

Percentage of sudden accelerations (positive and negative)

Percentage of time at non-constant speed

The system compares each of the attributes of the user telemetry with the best driver of the cluster. If the difference exceeds a threshold, the eco-advice associated with the attribute will be issued. For example, if a user drives at non-constant speed during 20 per cent of the trip and the best driver of the cluster drove at non-constant speed during 5 per cent the trip, the system will issue the voice output: "Do not change the speed so often".

\section{Achievements}

Gamification has several methods to get the attention of the user depending on the type of player. [41] defines four types of players: ambitious, winners, sociable and explorers. The ambitious players want to win in competitions and are encouraged with ranking. Sociable players want to create a friends network and contacts. The mechanisms used for this type of user are friend's lists, forums and chats. Explorer users want to discover new things and are motivated through the implementation of complex achievements. Finally, the winner profile users want to achieve recognition, so the publication of achievements can be used to motivate them.

Therefore, we can conclude that the achievements are an important element for many people in order to encourage them to save fuel and motivate them to continually use the eco-driving assistant. This method has a positive impact on the user to reach a pre-set of objectives and is based on the concept of "status". For this reason, we have incorporated the following achievements to our eco-driving assistant:

Having obtained 5 points by using the system

Having obtained 7 points by using the system

Having obtained 10 points by using the system

Complete a lap without accelerating sharply

Complete a lap without decelerating sharply

Positive Kinetic Energy over $0.30 \mathrm{~m} / \mathrm{s}^{2}$

Positive Kinetic Energy over $0.26 \mathrm{~m} / \mathrm{s}^{2}$

Average deviation speed over 1.6

Avoid driving at high speed

Avoid driving at high gear

\section{Customizing the Fuzzy Logic Rules and the Boundaries of the Achievements}

Eco-driving techniques are based on the driver behavior to reduce fuel consumption. The main advantage of this solution is that it is valid for any vehicle regardless of its technology. However, its effectiveness depends on the will of the user.

Efficient driving rules must be adapted for each vehicle and road conditions (weather and traffic state) in order to avoid the discouragement of the driver. Otherwise, the user may not use the proposal. We must bear in mind that the impact of accelerations, decelerations, vehicle speed and engine speed depends on the vehicle characteristics. For example, if the vehicle is old, the maximum speed from which the fuel consumption grows exponentially consumption will be lower than in modern vehicles that have aerodynamic improvements. Weather and road conditions also have an important effect on energy consumption, e.g.: a lowering of atmospheric temperature about $10{ }^{\circ} \mathrm{C}$ increases the fuel consumption around $4 \%$ [42].

In this paper, we propose to estimate the thresholds of the fuzzy rules and the achievements based on the telemetry from other vehicles belonging to the cluster (see subsection A "Identification of users with similar characteristics") and the own. The procedure is as follows:

1) Choose the " $n$ " driving samples with lower ratio "real fuel consumption / mixed fuel consumption provided by the manufacturer" from the driver cluster.

2) Calculate the third quartile for each input variable from the driving sample. 
3) The limit will be the average value of the third quartile taking into account all selected driving samples.

E.g.: We want to get the limit for the acceleration. Table 4 shows the driving samples on the driver cluster. The first column contains the ratio obtained by the driver. This value is used to select the samples. The following columns capture the intensity of the accelerations. We are assuming that each driver accelerated four times.

The proposal chooses driver $\mathrm{A}$ and $\mathrm{D}$, who have obtained lower ratio ( 0.23 and 0.22 , respectively). Then, we select the third quartile for the driver A (2.25) and D (2.39). Finally, the threshold will be the average value from driver A and B, 2.39 $\mathrm{m} / \mathrm{s}^{2}$ in that case. Therefore, if the intensity of acceleration is higher than this number, driver is speeding up sharply.

\section{E. Non-Intrusive Communication with the User}

The communication interface from the eco-driving assistant is very important. Distractions due to the manipulation of devices such as GPS receivers or mobile phones are the cause of a large number of accidents [43]. When designing an in-vehicle information system it is important to ensure that the recommendations and the method to convey these tips do not negatively affect cognitive processing and driving performance [44]. The eco-driving assistant has to be as less intrusive as possible. Instructions using voice output are less distracting and more usable than those systems presenting the information on a visual display [45]. However, an accurate speech recognizer and a clear voice user interface are necessary [44].

Our Android app (eco-driving assistant) uses voice output such as: "Release throttle" or "Shift gears" in order to warn the user when he or she performs an inefficient action during the driving. The driving score and eco-driving tips based on comparison with other users are shown on the mobile screen when the trip finishes and are issued by the mobile speaker. In addition, the driver can match their results with others users when the vehicle is stopped.

On the other hand, the user interface is divided into two parts during the driving. The top notifies the user about the efficiency of the driving using a color code (table 5). The bottom shows an image related to the eco-driving advice with most mistakes the user. This user interface is very sim-

\begin{tabular}{llllll} 
& & & & \\
Driver & Ratio & & Acceleration $\left(\mathrm{m} / \mathrm{s}^{2}\right)$ & \\
\hline A & 0.23 & 1 & 1.5 & 2 & 3 \\
\hline B & 1.5 & 0.99 & 2 & 2.3 & 4 \\
\hline D & 0.22 & 0.89 & 1.33 & 2.27 & 2.77 \\
\hline E & 2 & 1.22 & 1.66 & 1.77 & 3 \\
\hline F & 3 & 0.45 & 1 & 3 & 3 \\
\hline
\end{tabular}

Table 4. Driver cluster

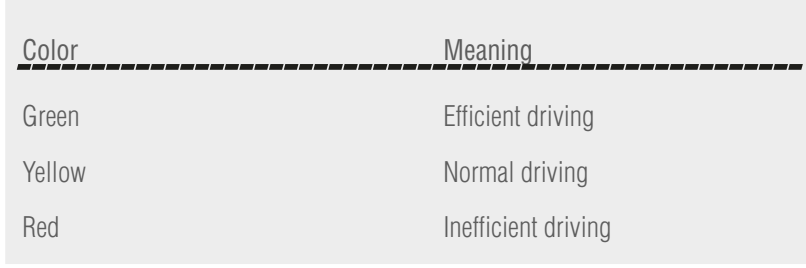

Table 5. Color code used in the user interface

ple in order to avoid an increase in the cognitive load from the driver. Figure 3 shows the Android app during the tests.

\section{F. Longitudinal Vehicle Dynamics Model}

The input variables and the rules of the fuzzy logic system are based on the longitudinal vehicle dynamics given by the following equation:

$$
m_{v} \vec{a}=\vec{F}_{t}(t)-\left(\vec{F}_{a}(t)+\vec{F}_{r}(t)+\vec{F}_{g}(t)\right)
$$

where $\vec{F}_{t}(t)$ is the traction force delivered by the car engine, $m_{v}$ the vehicle's mass, $\vec{F}_{a}(t)$ the aerodynamic force, $\vec{F}_{r}(t)$ the rolling force, $\vec{F}_{g}(t)$ the gravity force which is valid only if the vehicle is moving along a non-horizontal road, and $\vec{a}$ the vehicle's acceleration.

The engine-generated tractive effort is given by:

$$
F_{t}=\frac{M_{e} \varepsilon_{0} n_{d}}{r}
$$

where $F_{t}$ is the engine-generated tractive effort, $M_{e}$ is the engine torque in $\mathrm{Nm}, \varepsilon_{0}$ is the overall gear reduction ratio, $n_{d}$ is the mechanical efficiency of the driveline, and $\mathrm{r}$ is the radius of drive wheels in meters.

The aerodynamic force (4) depends on the speed and the vehicle shape.

$$
F_{a}=\frac{1}{16} C_{x} \times S \times v^{2}
$$

where $C_{x}$ is the drag force, $S$ is the vehicle's front surface $\left(\mathrm{m}^{2}\right)$, and $v$ the vehicle speed $(\mathrm{m} / \mathrm{s})$.

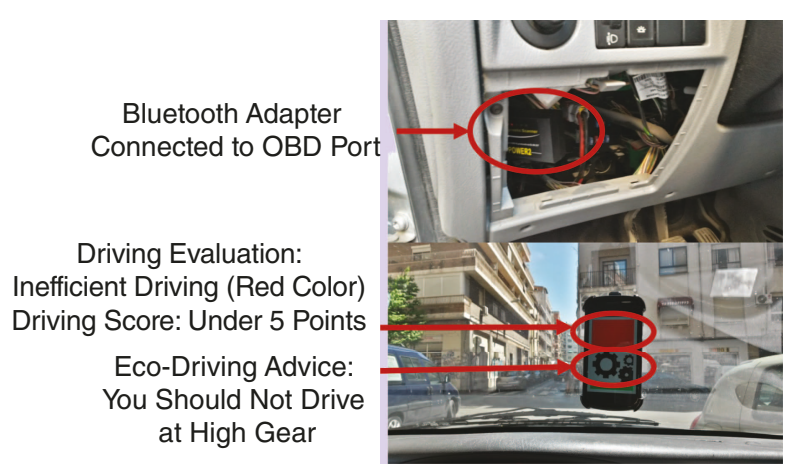

FIG 3 Awareness game architecture. 


\begin{tabular}{lccccc} 
Vehicle & Route & Maximum Power & Maximum Torque & Weight & $\begin{array}{c}\text { Mixed Fuel } \\
\text { Consumption }\end{array}$ \\
\hline Ford Fusion & A & $55.2 \mathrm{~kW}$ at 5700 R.P.M & 124 Nm at 3500 R.P.M & $1157 \mathrm{~kg}$ & $6.5 \mathrm{l} / 100 \mathrm{~km}$ \\
Citroen C5 & B & $103 \mathrm{~kW}$ at 4000 R.P.M & $320 \mathrm{Nm}$ at 2000 R.P.M & $1683 \mathrm{~kg}$ & $5.8 \mathrm{l} / 100 \mathrm{~km}$ \\
Citroen Xsara Picasso & C & $80 \mathrm{~kW}$ at 4000 R.P.M & 240 Nm at 1750 R.P.M & $1398 \mathrm{~kg}$ & $5.1 \mathrm{l} / 100 \mathrm{~km}$
\end{tabular}

Table 6. Technical characteristics of Ford Fusion 1.4 used in Route $A$

Rolling force can be calculated using the following equation:

$$
F_{r}=\mu \times P
$$

where $P$ is the vehicle mass $(\mathrm{kg})$ and $\mu$ is the rolling resistance coefficient $(\mu)$ whose value depends on a great number of parameters such as: the surface, the radius of the tire, the weight, the tire pressure, the temperature and the speed. However, we can estimate the coefficient using the following equation:

$$
\mu=\frac{k}{100}\left[5.1+\frac{5.5+9 p}{p n}+\frac{8.5+3 p}{p n} *\left(\frac{\mathbf{x}_{2}}{100}\right)^{2}\right]
$$

where $k$ is a coefficient dependent on the type of tire $(0.8$ for radial tires and 1 for diagonal tires), $p$ is the weight per tire (t), $p n$ is the tire pressure $\left(\mathrm{Kg} / \mathrm{cm}^{2}\right)$ and $\mathrm{x}_{2}$ is the vehicle speed $(\mathrm{Km} / \mathrm{h})$.

Gravity has a direct impact on the vehicle when we go up or down a slope because we have to overcome this force which depends on the mass of the vehicle and the slope. When we go down, this force helps the movement, accelerating the vehicle. It is calculated using the following equation:

$$
F_{g}=P \times g \times \sin \propto
$$

where $\mathrm{P}$ is the vehicle mass $(\mathrm{kg}), g$ is the gravitational constant and $\propto$ is the road slope angle.

\section{Results}

The eco-driving assistant was deployed on Android mobile devices: Nexus S, Nexus 7, Galaxy Nexus and Htc One V. Nexus S and Htc One V have equipped with an ArmV7 processor at $1 \mathrm{GHz}, 512 \mathrm{MB}$ of RAM. Nexus 7 has a Tegra 3 processor at $1.2 \mathrm{GHz}$ and $1 \mathrm{~GB}$ of RAM. Galaxy Nexus has a ArmV9 processor at $1.2 \mathrm{Ghz}$ and $1 \mathrm{~GB}$ of RAM.

The OBDLink OBD Interface Unit from ScanTool.Net [46] was used to get the relevant data (vehicle speed, fuel consumption, engine speed and acceleration) from the internal vehicle's CAN bus. The OBDLink OBD Interface Unit contains the STN1110 chip that provides an acceptable sample frequency for the system. In our tests, we obtain two samples per second.

In order to evaluate the energy savings achieved when using the proposed social game, 2160 test drives have been performed, using three different models of vehicles with 36 different drivers. The tests were performed in Granada (route A), Seville (route B) and Madrid (route $\mathrm{C}$ ) during the months of March, April, and May 2013. Initial tests (without ecodriving tips) were completed during 2012. Routes have urban road, secondary road and highway. All tests were completed under similar conditions (time, traffic, and weather) in order to make a fair comparison.

Route A length is $8.3 \mathrm{Km}$. This track has a $36.64 \%$ of highway and a $63.86 \%$ of urban road. The trip time estimated by Google under normal conditions is 18 minutes. Route B length is $8.3 \mathrm{Km}$. This track has a $48.51 \%$ of highway, $15.84 \%$ of secondary road and a $35.65 \%$ of urban road. In this case, the trip time estimated by Google under normal conditions is 15 minutes. Finally, route $\mathrm{C}$ has a length of $9.38 \mathrm{Km}$. This track has a $54.37 \%$ of highway, $23.45 \%$ of secondary road and a $22.17 \%$ of urban road. In this case, the trip time estimated by Google under normal conditions is 15 minutes. The slope is not very steep in all cases.

A Ford Fusion 1.4 (2005) was used in route A. The users drive a Citroen C5 (2010) on route B. Finally, drivers employed a Citroen Xsara Picasso 1.6 HDI (2002) on route C. Table 6 show the vehicle characteristics in more detail.

Drivers were divided into two groups for each route: control and experimental. All participants made an initial test (60 rounds) without eco-driving tips. Users from the control group did not participate in the social game. In this case, drivers only received classic eco-driving tips. For example, the assistant alerts the user when it detects that vehicle speed exceeds a limit.

In contrast, drivers from experimental group can see their score and the achievements, as well as match the results with other users. In addition, eco-driving advice are based on the comparison of the driving with other telemetry obtained under similar conditions.

Table 7, 8 and 9 capture the average fuel consumption obtained during 60 tests for each driver on route A, B and C, respectively. The improvement was $8.91 \%$ in route $A, 9.66 \%$ in route $\mathrm{B}$, and $7.38 \%$ in route $\mathrm{C}$ when we compare the fuel consumption between control and experimental group. Moreover, we can see that the drivers from experimental group tends to obtain a similar fuel consumption compared to the control group. The standard deviation was 0.26 (route A), 0.38 (route B), 0.35 (route C) for the control group, while the experimental group obtains 0.09 (route A), 0.10 (route B) and 0.12 (route $\mathrm{C}$ ).

In addition, the results show that sometimes the improvements do not happen or are not very significant when the user does not have the gamification tool. For example, the average fuel consumption obtained by driver A was 7.76 l/100 km 
without eco-driving tips and 7.81 1/100 km with assistant (gamification tools disabled). This conclusion was also obtained by other researchers [3] [5].

In order to validate that the energy savings when we employs the gamification tool are not due to random factors, the two samples t-test assuming unequal variances [47] has been used. Table 10, 11, 12 capture the average fuel consumption and the values of t-test for control and experimental group. Considering the null hypothesis as: "there is no improvement in fuel consumption levels when using the awareness game" and calculating the p-value for each driver we obtain the following values: $8.39301 \mathrm{E}-38$ (Route A), 1.88644E-36 (Route B), 2.78604E-35 (Route C). All values are below the 0.05 threshold). Therefore, the null hypothesis (under the 0.05 threshold) can be rejected.

Table 13 shows the telemetry and the score obtained by the two groups during 60 rounds and the initial test. Control group improves all variables compared to initial test. However, the improvement is even greater when we use gamification (experimental group). It is important to highlight that users from this group reduce the frequency and intensity of the slowdowns. The sudden accelerations only have a negative effect on energy consumption when they are followed by downturns. In these cases the energy is unused as lost heat through the brakes of the vehicle.

Table 14 captures the number of drivers who earned each badge. Drivers with the game features enabled (experimental group), unlocked more achievements than users without the game features active.

The major difference introduced by the use of the gamification is appreciated in the speed pattern obtained by drivers with aggressive profiles. Figure 4 compares the speed pattern from a driver without social game (A) with the speed profile got by a driver from experimental group (B) on route A. Both are aggressive drivers. Figure 4 shows that Driver A drives faster than the driver B. This implies that driver A has to brake with more frequency and intensity. Therefore, the wasted energy is increased. In conclusion, the awareness

\begin{tabular}{|c|c|c|c|c|}
\hline \multirow[b]{2}{*}{ Driver } & \multicolumn{4}{|c|}{ Route A } \\
\hline & Control Group & $\begin{array}{l}\text { ial Test } \\
\text { Experimental Group }\end{array}$ & $\begin{array}{l}\text { Control } \\
\text { Group }\end{array}$ & $\begin{array}{l}\text { Experimental } \\
\text { Group }\end{array}$ \\
\hline A & 6.9 & 7.11 & 6.28 & 6.11 \\
\hline B & 7.25 & 6.78 & 6.84 & 6.33 \\
\hline C & 7.29 & 7.17 & 7.16 & 6.25 \\
\hline D & 7.06 & 6.91 & 6.82 & 6.25 \\
\hline$E$ & 7.17 & 7.21 & 6.8 & 6.24 \\
\hline$F$ & 7.39 & 6.68 & 6.97 & 6.05 \\
\hline
\end{tabular}

Table 7. Average fuel consumption (l/100 km) obtained during 60 tests for each driver on Route $A$.

\begin{tabular}{|c|c|c|c|c|}
\hline \multirow[b]{2}{*}{ Driver } & \multicolumn{4}{|c|}{ Route B } \\
\hline & Control Group & $\begin{array}{l}\text { tial Test } \\
\text { Experimental Group }\end{array}$ & $\begin{array}{l}\text { Control } \\
\text { Group }\end{array}$ & $\begin{array}{l}\text { Experimental } \\
\text { Group }\end{array}$ \\
\hline A & 7.76 & 7.87 & 7.81 & 6.65 \\
\hline B & 7.93 & 8.02 & 7.86 & 6.87 \\
\hline C & 7.85 & 7.90 & 7.43 & 6.65 \\
\hline D & 7.94 & 7.92 & 6.69 & 6.60 \\
\hline E & 7.81 & 7.95 & 7.31 & 6.86 \\
\hline $\mathrm{F}$ & 7.91 & 7.88 & 7.51 & 6.77 \\
\hline
\end{tabular}

Table 8. Average fuel consumption (l/100 km) obtained during 60 tests for each driver on Route $B$

\begin{tabular}{|c|c|c|c|c|}
\hline \multicolumn{5}{|c|}{ Route C } \\
\hline Driver & Control Group & $\begin{array}{l}\text { ial Test } \\
\text { Experimental Group }\end{array}$ & $\begin{array}{l}\text { Control } \\
\text { Group }\end{array}$ & $\begin{array}{l}\text { Experimental } \\
\text { Group }\end{array}$ \\
\hline A & 6.35 & 6.39 & 6.02 & 5.89 \\
\hline B & 6.88 & 6.40 & 6.83 & 5.7 \\
\hline C & 6.76 & 6.48 & 6.19 & 5.55 \\
\hline D & 6.47 & 6.31 & 5.68 & 5.56 \\
\hline$E$ & 6.34 & 6.64 & 5.88 & 5.55 \\
\hline $\mathrm{F}$ & 6.42 & 6.81 & 6.04 & 5.69 \\
\hline
\end{tabular}

Table 9. Average fuel consumption (l/100 km) obtained during 60 tests for each driver on Route $\mathrm{C}$
Samples
360
T Stat
13.83
$\mathrm{P}(\mathrm{T}<=\mathrm{t})$ two tail
$8.39301 E-38$

Table 10. T-Test on Route A

$\begin{array}{ll}\text { Samples } & 360 \\ \text { T Stat } & 13.37 \\ \mathrm{P}(\mathrm{T}<=\mathrm{t}) \text { two tail } & 1.88644 \mathrm{E}-36\end{array}$

Table 11. T-Test on Route B

$\begin{array}{ll}\text { Samples } & 360 \\ \text { T Stat } & 13.09 \\ \mathrm{P}(\mathrm{T}<=\mathrm{t}) \text { two tail } & 2.78604 \mathrm{E}-35\end{array}$

Table 12. T-Test on Route $\mathrm{C}$ 


\begin{tabular}{|c|c|c|c|c|}
\hline & Route. & _Initial Test & $\begin{array}{l}\text { Control } \\
\text { Group }\end{array}$ & $\begin{array}{l}\text { Experimental } \\
\text { Group }\end{array}$ \\
\hline \multirow{3}{*}{$\begin{array}{l}\text { Average acceleration } \\
\left(\mathrm{m} / \mathrm{s}^{2}\right)\end{array}$} & $A$ & 0.88 & 0.54 & 0.47 \\
\hline & B & 0.70 & 0.6 & 0.58 \\
\hline & C & 0.61 & 0.72 & 0.61 \\
\hline \multirow{3}{*}{$\begin{array}{l}\text { Average deceleration } \\
\left(\mathrm{m} / \mathrm{s}^{2}\right)\end{array}$} & A & 0.85 & 0.56 & 0.52 \\
\hline & B & 0.69 & 0.6 & 0.55 \\
\hline & C & 0.75 & 0.6 & 0.54 \\
\hline \multirow{3}{*}{$\begin{array}{l}\text { Positive kinetic } \\
\text { energy }\left(\mathrm{m} / \mathrm{s}^{2}\right)\end{array}$} & A & 0.55 & 0.33 & 0.26 \\
\hline & B & 0.53 & 0.36 & 0.28 \\
\hline & C & 0.40 & 0.28 & 0.26 \\
\hline \multirow[t]{3}{*}{ High engine speed } & A & $12.57 \%$ & $11.14 \%$ & $3 \%$ \\
\hline & B & $0 \%$ & $0.18 \%$ & $0 \%$ \\
\hline & C & $7.71 \%$ & $6.50 \%$ & $1.37 \%$ \\
\hline \multirow[t]{3}{*}{ High speed } & A & $4.64 \%$ & $0 \%$ & $0 \%$ \\
\hline & B & $8.50 \%$ & $2.07 \%$ & $0 \%$ \\
\hline & C & $6.93 \%$ & $2.44 \%$ & $0 \%$ \\
\hline \multirow{3}{*}{$\begin{array}{l}\text { Standard deviation of } \\
\text { vehicle speed }\end{array}$} & $A$ & 3 & 1.74 & 1.45 \\
\hline & B & 2.29 & 2.08 & 1.83 \\
\hline & C & 2.09 & 1.95 & 1.64 \\
\hline \multirow[t]{3}{*}{ Score $(0-10)$} & A & 1.5 & 3.56 & 7.00 \\
\hline & B & 2.25 & 2.9 & 6.02 \\
\hline & C & 2.59 & 4.66 & 7.02 \\
\hline
\end{tabular}

Table 13. Results obtained during 60 tests for each group.

$\begin{array}{lll} & \begin{array}{l}\text { Control } \\ \text { Group }\end{array} & \begin{array}{l}\text { Experimental } \\ \text { Group }\end{array} \\ \text { Obtain } 5 \text { points } & 2 & 18 \\ \text { Obtain } 7 \text { points } & 1 & 8 \\ \text { Obtain } 10 \text { points } & 0 & 0 \\ \text { Complete a lap without accelerating sharply } & 11 & 15 \\ \text { Complete a lap without decelerating sharply } & 9 & 17 \\ \text { PKI Value }<0.30 \mathrm{~m} / \mathrm{s}^{2} & 4 & 16 \\ \text { PKI Value }<0.26 \mathrm{~m} / \mathrm{s}^{2} & 1 & 5 \\ \text { Average deviation speed over } 1.6 & 1 & 8 \\ \text { Avoid driving at high speed } & 9 & 18 \\ \text { Avoid driving at high gear } & 1 & 7\end{array}$

Table 14. Number of drivers who earned each badge game has a positive impact on the softening of the driving. The gamification encourages users to comply with the ecodriving rules, especially when the driver has an aggressive driving profile.

Figure 5 captures the progression of average fuel consumption for control group on route A, B, and C. In this case, the fuel consumption improved initially. However, after a short period of time, fuel consumption is like the beginning. Drivers do not receive any encouragement to apply the rules, and therefore, they returns to their previous driving habits.

On the other hand, the drivers from the experimental group try to drive efficiently during all tests when using the gamification tools (figure 6). Finally, we must highlight that the driver takes several days to adapt to the use of the device in all cases. However, the user from the experimental group requires fewer days than the driver from the control group.

The conclusion is that the efficient driving assistant with gamification tools reduces fuel consumption compared to the results obtained when the assistant shows only eco-driving tips. However, we always have to keep in mind that the improvement in fuel consumption depends on two

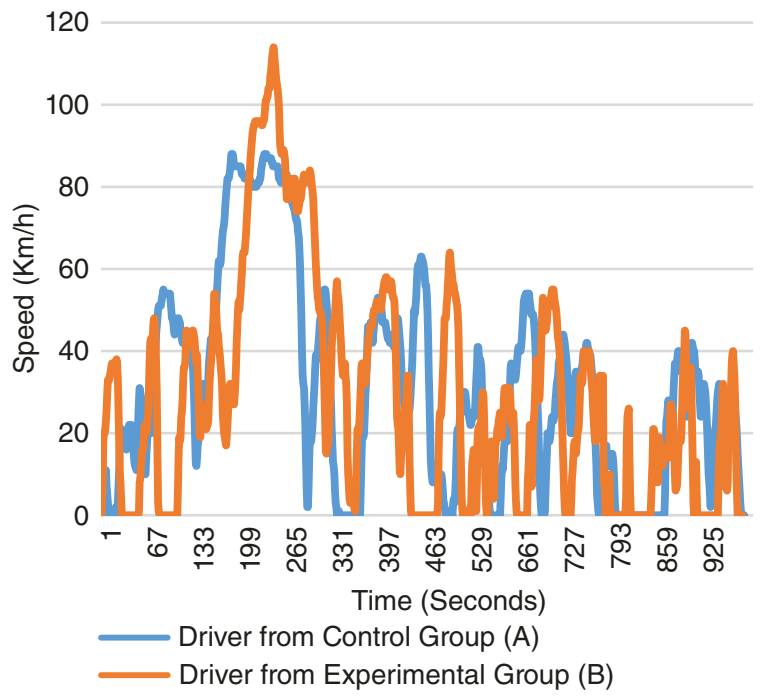

FIG 4 Comparison of speed profiles.

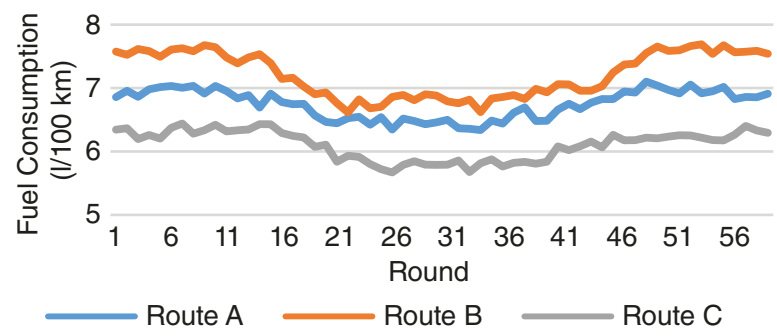

FIG 5 Fuel consumption progression after 60 rounds (control group). 


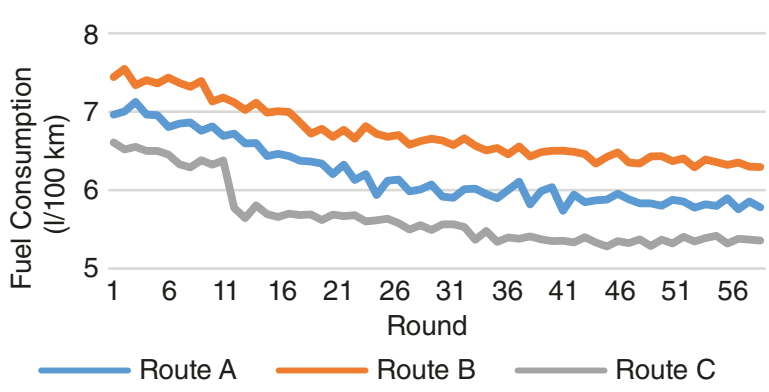

FIG 6 Fuel consumption progression after 60 rounds (experimental group).

factors: the driver and the environment. The eco-driving technique allows us to save fuel whenever environmental conditions are appropriate.

\section{Conclusions}

In this paper, we have proposed to use gamification tools in order to encourage drivers to change their driving habits. In addition, the solution obtains the most relevant eco-driving tips by comparing the vehicle telemetry with other users with similar characteristics. The selection of the eco-driving tips that are shown to the user is very important in order to avoid a high cognitive load. Other solutions do not highlight which are the most important tips in order to improve fuel consumption.

The system evaluates the driving style from the viewpoint of energy efficiency and assigns a score to each user. Then, users are grouped for comparison. The construction of the different user groups is performed taking into account: time, average speed, the percentage of time that the vehicle was stopped, the percentage of time that the driver drove at more than $50 \mathrm{~km} / \mathrm{h}$, the stop rate, the traffic events, and the weather conditions. The proposed system compares the telemetry of the best driver (highest score) with other users to get the eco-driving advice that should be shown to the user. Drivers can share their scores with other users or post them on external social networks like Facebook or Twitter.

The implemented awareness game has been validated on three different routes by 36 drivers. The results show the positive impact on fuel consumption when the user employs the system. However, the main contribution of this solution is that the user maintains the interest in complying with the rules over time. On the other hand, we observed that the driver takes several days to adapt to the use of the device. For this reason, the feedback provided by the system to the user in order to avoid that the driver partially loses his or her interest is very important.

As future work, we want to observe the effect of the solution in driving habits with a larger number of drivers, during a longer period of time, and under different road conditions. To accomplish this task, we want to adapt the proposal not to require the OBD adapter. In this case, we will only employ the sensors from the mobile phone to evaluate the driving style. For example, we can get the vehicle speed from the GPS sensor. This solution will allow us to broaden the number of participants significantly since many of them were reluctant to connect the OBD adapter to the vehicle bus. Furthermore, this new proposal will offer support for older vehicles that do not comply with the OBD2 protocol. Finally, it can also be interesting to study whether after switching off the system by a driver, he or she continues to maintain good driving habits or returns back to its original driving style.

\section{Acknowledgment}

The research leading to these results has received funding from the "HERMES-SMART DRIVER" project TIN201346801-C4-2-R within the Spanish "Plan Nacional de I+D+I" under the Spanish Ministerio de Economía y Competitividad and from the Spanish Ministerio de Economía y Competitividad funded projects (co-financed by the Fondo Europeo de Desarrollo Regional (FEDER)) IRENE (PT-2012-1036370000), COMINN (IPT-2012-0883-430000) and REMEDISS (IPT-2012-0882-430000) within the INNPACTO program.

\section{About the Authors}

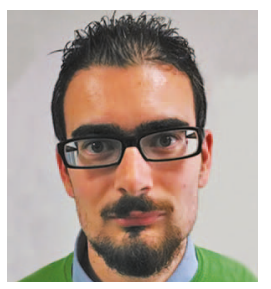

V. Corcoba Magaña received his M.Sc. degree in computer science from the University of Granada, Granada, Spain, in 2009, and the Ph.D. degree in telematics engineering from the Carlos III University of Madrid, Leganes, Spain, in 2014. He is a research of the telematics department at the University Carlos III of Madrid. He has also more than four years of experience working on research projects related to bioinformatics, pervasive computing, and Artificial Intelligence. He is the author of four books, and more than 15 articles about energy efficient on vehicles. His present research is focused on efficient driving, machine learning, mobile devices and visual object recognition. Other research interests include data mining, pattern recognition and bioinformatics. V. Corcoba Magaña has obtained two fellowships: Senior Student fellowship (2008) and Research fellowship (2010) from Ministry of Education and Science.

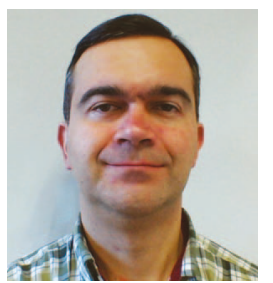

M. Muñoz-Organero (M'08) received the M.Sc. degree in telecommunications engineering from the Polytechnic University of Catalonia, Barcelona, Spain, in 1996, and the Ph.D. degree in telecommunications engineering from the Carlos III University of Madrid, Leganes, Spain, in 2004. He is a Professor of telematics engineering at the Carlos III University of Madrid. He has also more than four years of experience working for the telecommunications industry in companies such as Telefonica R\&D and Lucent Technologies, both in Madrid, Spain. His research projects have included topics related to ambient intelligence, ITS, open architectures for 
e-learning systems, open service creation environments for next-generation networks, advanced mobile communication systems, pervasive computing, and convergent networks. He has participated in several European-funded projects such as E-LANE and Spanish-funded projects such as MOSAIC learning, Learn3 and OSAMI. He is currently the lead researcher of the Spanish-funded ARTEMISA, HAUS, COMINN, REMEDISS and IRENE projects. He is also the IP of the GEEWHEZ EU-FP7 project and an MC member of TU1305 EU funded COST action about social networks and travel behavior.

\section{References}

[1] J. Barbé and G. Boy, "On-board system design to optimize energy management," in Proc. European Annu. Conf. Human Decision-Making Manual Control, Valenciennes, France, Sept. 27-29, 2006.

[2] O. H. Koskinen, "Improving vehicle fuel economy and reducing emis sions by driving technique," in Proc. 15th ITS World Congr., New York, Nov. 15-20, 2008 .

[3] T. Onoda, "IEA policies-G8 recommendations and an afterwards," Energy Policy, vol. 37, no. 10, pp. 3823-3831, 2009.

[4] D. Hari, C. J. Brace, C. Vagg, J. Poxon, and L. Ash, "Analysis of a driver behaviour improvement tool to reduce fuel consumption," in Proc. Int. Conf. Connected Vehicles Expo., Dec. 12-16, 2012, pp. 208-213.

[5] H. Lee, W. Lee, and Y. K. Lim, "The effect of eco-driving system towards sustainable driving behavior," in Proc. 28th Int. Conf. Extended Abstracts Human Factors Computing Systems, 2010, pp. 4255-4260.

[6] K. Erenli, "The impact of gamification: A recommendation of scenarios for education," in Proc. 15th Int. Conf. Interactive Collaborative Learning, Sept. 26-28, 2012, pp. 1-8.

[7] J. Berengueres, F. Alsuwairi, N. Zaki, and T. Ng, "Emo-bin: How to recycle more by using emoticons," in Proc. 8th ACM/IEEE Int. Conf. Human-Robot Interaction, Mar. 3-6, 2013, pp. 397-397.

[8] F. L. Law, Z. M. Kasirun, and C. K. Gan, "Gamification towards sustainable mobile application," in Proc. 5th Malaysian Conf. Software Engineering, Dec. 13-14, 2011, pp. 349-353.

[9] (2013, Apr. 24) INNOV 8. [Online]. Available: http://www-01.ibm.com/ software/solutions/soa/innov8/index.html

[10] H. Liimatainen, "Utilization of fuel consumption data in an ecodriving incentive system for heavy-duty vehicle drivers," IEEE Trans. Intell. Transport. Syst., vol. 12, no. 4, pp. 1087-1095, Dec. 2011.

[11] A. Ryosuke, N. Yasuhide, and O. Daisuke, "Development of a system to promote eco-driving and safe-driving," in Smart Spaces and Next Generation WiredWireless Networking, vol. 6294. Berlin/Heidelberg, Germany: Springer, 2010, pp. 207-218.

[12] D. Vara, E. Macias, S. Gracia, A. Torrents, and S. Lee, "Meeco: Gamifying ecology through a social networking platform," in Proc. IEEE Int. Conf. Multimedia Expo., July 11-15, 2011, pp. 1-6.

[13] S. Godavarty, S. Broyles, and M. Parten, "Interfacing to the on-board diagnostic system," in Proc. 52nd IEEE-VTS Fall Vehicular Technology Conf., 2000, vol. 4, pp. 2000-2004.

[14] H. Johansson, P. Gustafsson, M. Henke, and M. Rosengren, "Impact of eco-driving on emissions," in Proc. 12th Symp. Transport Air Pollution Conf., Avignon, France, 2003.

[15] J. van Mierlo, G. Maggetto, E. van de Burgwal, and R. Gense, "Driving style and traffic measures-influence on vehicle emissions and fuel consumption," Proc. Inst. Mech. Eng. D: J. Automobile Eng., vol. 218, pp. 43-50, Jan. 1, 2004.

[16] M. Barth, S. Mandava, K. Boriboonsomsin, and X. Haitao, "Dynamic eco-driving for arterial corridors," IEEE Forum Integr. Syst. Transp. Syst., pp. 182-188, 2011.

[17] M. A. S. Kamal, M. Mukai, J. Murata, and T. Kawabe, "On board ecodriving system for varying road-traffic environments using model predictive control," in Proc. IEEE Int. Conf. Control Applications, Sept. 8-10, 2010, pp. 1636-1641.

[18] A. E. af Wåhlberg, "Long-term effects of training in economical driving: Fuel consumption, accidents, driver acceleration behavior and technical feedback," Int. J. Ind. Ergon., vol. 37, no. 4, pp. 333-343, Apr. 2007.

[19] G. H. Walker, N. A. Stanton, and M. S. Young, "Hierarchical task analysis of driving: A new research tool," in Contemporary Ergonomics, M. A. Hanson, Ed. London: Taylor and Francis, 2001, pp. 435-440.

[20] J. Tulusan, L. Soi, J. Paefgen, M. Brogle, and T. Staake, "Eco-efficient feedback technologies: Which eco-feedback types prefer drivers most?" in Proc. IEEE Int. Symp. World Wireless, Mobile Multimedia Networks, June 20-24, 2011, pp. 1-8.
[21] K. Boriboonsomsin, A. Vu, and M. Barth, "Eco-driving: Pilot evaluation of driving behavior changes among U.S. drivers," Center Environ. Res. Technol., Univ. California Transportation Center, Riverside, CA, 2010.

[22] I. B. Dhaou, "Fuel estimation model for eco-driving and eco-routing," in Proc. IEEE Intelligent Vehicles Symp. (IV), June 5-9, 2011, pp. 37-42.

[23] Y. Saboohi and H. Farzaneh, "Model for developing an eco-driving strategy of a passenger vehicle based on the least fuel consumption," Appl. Energy, vol. 86, no. 10, pp. 1925-1932, Oct. 2009.

[24] N. Xiong, J. He, J. H. Park, D. Cooley, and Y. Li, "A neural network based vehicle classification system for pervasive smart road security," Universal Comp. Sci., vol. 15, no. 5, pp. 1119-1142, 2009.

[25] S. Yamabe, R. Zheng, K. Nakano, and Y. Suda, "Physical fatigue comparison of eco-driving and normal driving," J. Syst. Des. Dyn., vol. 5, no. 5, pp. 994-1004, 2011.

[26] N. Haworth and M. Symmons, "The relationship between fuel economy and safety outcomes," Monash Univ. Accident Research Centre, 2001, pp. 1-57.

[27] Google. (2014, Aug.). Google driverless project. [Online]. Available: http://en.wikipedia.org/wiki/Google_driverless_car

[28] (2014, Aug.). SARTRE project. [Online]. Available: http://www.sartreproject.eu/en/Sidor/default.aspx

[29] B. Asadi and A. Vahidi, "Predictive cruise control: Utilizing upcoming traffic signal information for improving fuel economy and reducing trip time," IEEE Trans. Control Syst. Technol., vol. 19, no. 3, pp. 707-714, May 2011.

[30] A. de la Escalera, J. M. Armingol, and M. Mata, "Traffic sign recognition and analysis for intelligent vehicles," Image Vis. Comput., vol. 21, no. 3, pp. 247-258, Mar. 1, 2003.

[31] Y. Aoyagi and T. Asakura, "A study on traffic sign recognition in scene image using genetic algorithms and neural networks," in Proc. IEEE 22nd Int. Conf. Industrial Electronics, Control, Instrumentation, Aug. 5-10, 1996, vol. 3, pp. 1838-1843.

[32] C. Bahlmann, Y. Zhu, V. Ramesh, M. Pellkofer, and T. Koehler, "A system for traffic sign detection, tracking, and recognition using color, shape, and motion information," in Proc. IEEE Intelligent Vehicles Symp., June 6-8, 2005, pp. 255-260.

[33] N. Ishikawa, K. Onda, K. Watanabe, K. Kobayashi, and Y. Kurihara, "Mobile phone application for ecodriving," in Proc. SICE Annu. Conf., Aug. 18-21, 2010, pp. 2424-2447.

[34] G. Strazdins, A. Mednis, G. Kanonirs, R. Zviedris, and L. Selavo, "Towards vehicular sensor networks with Android smartphones for road surface monitoring," in Proc. 2nd Int. Workshop Networks Cooperating Objects (CONET), Electronic Proc. (CPSWeek), 2011, pp. 1-4.

[35] (2014, Aug.). Google play services. [Online]. Available: https://developer. android.com/google/play-services/games.html

[36] (2014, Aug.). DGT. [Online]. Available: http://infocar.dgt.es/etraffic/ rss_todas.xml

[37] (2014, Aug.). AEMET. [Online]. Available: http://www.aemet.es/es/ portada

[38] K. S. Nesamani and K. P. Subramanian, "Development of a driving cycle for intra-city buses in Chennai, India," Atmos. Environ., vol. 45, no. 31, pp. 5469-5476, Oct. 2011.

[39] R. J. Nairn, S. Partners, L. Economic Consultants, and H. Watson, "Victorian transport externalities study 3. Strategies for reducing emissions of greenhouse gases and ozone precursors from land-based transport," Report prepared for EPA, Melbourne, Australia, 1994.

[40] W. Frith and P. Cenek, "AA research: Standard metrics for transport and driver safety and fuel economy," Opus International Consultants Central Laboratories, Nov. 2012.

[41] R. A. Bartle, Designing Virtual Worlds. Berkeley, CA: New Riders, 2004.

[42] IDAE, "Handbook of efficient driving for drivers," Ministry of Industry, Energy and Tourism, Spain, 2005.

[43] Y. Dong, Z. Hu, K. Uchimura, and N. Murayana, "Driver inattention monitoring system for intelligent vehicles: A review," IEEE Trans. Intell. Transport. Syst., vol. 12, no. 2, pp. 596-614, 2011.

[44] M. Peissner, V. Doebler, and F. Metze, "Can voice interaction help reducing the level of distraction and prevent accidents? Meta-study on driver distraction and voice interaction," White Paper, May 19, 2011, p. 24.

[45] K. Young and M. Regan, "Driver distraction: A review of the literature," in Distracted Driving, I. J. Faulks, M. Regan, M. Stevenson, J. Brown, A. Porter, and J. D. Irwin, Eds. Sydney, NSW: Australasian College of Road Safety, 2007, pp. 379-405.

[46] (2014, Aug.). OBD2 Adapter. [Online]. Available: http://www.scantool.net

[47] J. J. O'Connor and and F. E. Robertson. Student's t-test. MacTutor History of Mathematics archive, Univ. St Andrews, Scotland. [Online]. Available: http://www-history.mcs.st-andrews.ac.uk/Biographies/ Gosset.html 